\title{
Psychological and socio-economic challenges faced by teen fathers: A narrative review
}

\author{
K. M. Rantho ${ }^{*}$, F. K. Matlakala ${ }^{2}$ \\ ${ }^{1 *}$ Department of Social Work, University of Limpopo, South Africa; ${ }^{2} \mathrm{Ph} . \mathrm{D}$. Candidate, Department of Social Work, \\ University of Limpopo, South Africa. \\ Email: ${ }^{1 *}$ rantho.magdeline@gmail.com, ${ }^{2}$ fransmatlakala@gmail.com
}

\section{Keywords}

Challenges, Parenthood, Psychological, Socioeconomic, Teen Fathers.

\section{Article History}

Received on $5^{\text {th }}$ October 2021

Accepted on $17^{\text {th }}$ October 2021

Published on $18^{\text {th }}$ October 2021

Cite this article

Rantho, K. M., \& Matlakala, F. K. (2021).

Psychological and socio-economic challenges

faced by teen fathers: A narrative review.

Humanities \& Social Sciences Reviews, 9(5), 62

67. https://doi.org/10.18510/hssr.2021.9510

Copyright @Author

Publishing License

This work is licensed under a Creative Commons Attribution-Share Alike 4.0 International License (c) (i) (?)

\begin{abstract}
Purpose of the study: The purpose of the study was to explore the psychological and socio-economic challenges faced by teen fathers.

Methodology: This was a narrative literature review study, wherein researchers relied on secondary data from peer-reviewed published articles. Published articles were purposively sampled from different search engines such as Google scholar, South African National ETD portal, Jstor, Sabinet and EBSCOhost. The selection criteria were also determined by restricted data from the year 2003 to 2020 with a 17 years' projection. The collected data was analysed thematically.
\end{abstract}

Main Findings: The study found that teenage boys are not immune to the challenges of parenthood. More like their counterparts, teen fathers experience psychological and socio-economic challenges as far as parenthood is concerned.

Application of the study: The lack of research on teen fathers creates an imbalance and leads people into believing that only teen mothers experience parenthood challenges. However, this study underpins that due to the lack of research on teen fathers, teen fathers experience various social ills such as stealing and dropping out of school due to the challenge of parenthood.

Novelty/Originality of the study: This study contributes positively to the arena of social service and assists social workers with guidelines to address teen fatherhood. By the virtue of their educational background, social workers can advocate for voiceless teen fathers and challenge the imbalances that invade their dignity and manhood.

\section{INTRODUCTION}

Teenage parenthood or teen parenthood is a predominant matter globally and South Africa is not an exception. However, Madiba and Nsiki (2017) state that teen parenthood research is mostly based on teen mothers with the exclusion of teen fathers because researchers believe that pregnancy affects teen mothers more than teen fathers. On that score, Quinlivan and Condon (2005) reiterate that the number of teen fathers is low and often is not reported because teen fathers can easily deny the pregnancy hence, more research is focused on teen mothers. In the same vein, Sheeran, Jones, Bernardin, Wood, and Doherty (2021) signposted that, unlike teen mothers, teen fathers are not keen on the whole issue of parenthood. Be that as it may, earlier findings by Mukuna (2020) found that young boys are at risk of being fathers at an early age because many intervention strategies focus on young mothers than them. Although the risks of parenthood can be harsh on teen mothers, it should not be an exception that teen fathers have no challenges (Matlakala, Makhubele \& Mashilo, 2018; Mukuna, 2020). For instance, teen fathers struggle before and after pregnancy due to the harsh reality of becoming a father particularly when they come from low-income backgrounds.

Chideya and Williams (2013) and Matlakala (2020) aver that young boys who are faced with the challenge of becoming teen fathers are exposed to risk factors such as dropping out of school to find jobs and finance their children's lives. However, it becomes hard for them to find a job while having no higher qualifications. Due to these socio-economic challenges, these teen fathers end up suffering from psychological distress which impairs the social and functional spheres of their lives (Quinlivan, \& Condon, 2005; Weber, 2012). Whilst other teen fathers take responsibility, others run away from their children which makes it hard for researchers to study the challenges that teen fathers face. According to Weber (2012), teen fathers' runway from their parental responsibilities due to societal judgment which also makes them remain in hiding. For example, many societal members do not only judge the teen fathers but also their families and claim that the families have not socialized their children well.

This paper is aimed at exploring the psychological and socio-economic challenges faced by teen fathers.

\section{BACKGROUND INFORMATION}

Both the conventional wisdom and existing research suggest that fathers' involvement is beneficial for children's development and well-being. This is supported by Berger and Langton (2011), Chili (2013), Maiden (2013) and 
Hodgson, Painter, Kilby and Hirst (2021) who postulated that a father-child relationship is desirable for numerous fathers either in the presence of the mother or alone. On the other hand, Fagan, Bernd, and Whiteman (2007) and Fletcher and Wolfe (2012) point out that the father-child relationship is recognised by development-oriented scholars as reciprocal. Although, more attention by researchers is directed to parents' reactions to their children (for example, socialisation). Chili (2013) found that a great number of fathers are not in a relationship with the mother of their children. Authors are of the view that some of the breakups are caused by the divergence of personality between the teen father and the child's mother. Such a clash of personality might be, for instance, that the teen father is abusing substances and the partner cannot tolerate that. The authors further established that most of the children may stay with their mothers or their mothers' families. Among those whose relationships with their partners ended, some developed a lack of interest in their children, whereas others opted to put their differences aside to concentrate on their children's well-being.

The majority of individuals in the community hold the view that teen fathers are irresponsible beings who do not care about their offspring. The stereotypical view is biased as other young fathers need to be active in the life of their children even though they are not in a romantic relationship with the mother of their child (Dudley, 2007; Chobany \& Hull, 2021). In addition, Chili (2013) found that some teen fathers opted to maintain their relationships with their partners as well as their children to "rectify" their fathers' past deeds. Respondents in Chili's study stated that they observed how they lived in poor conditions with their single mothers. They mentioned that they did not want their children to grow up as they did. As a result, they wanted to take responsibility for their children. These lead other teenagers to engage themselves in labour so that they could provide for their children and assume parental responsibilities. For instance, in a study conducted by Glikman (2004), one of the respondents stated that he would rather work two jobs, go to school and sleep only two hours a day, to ensure that he maintains his relationship with his child. That goes to show that teen fathers are not immune to the challenges of parenthood.

\section{RESEARCH METHODOLOGY}

There are two types of research, namely empirical and non-empirical research. In this paper, the researchers opted for non-empirical research where they reviewed the literature to highlight and describe existing literature on the challenges that are faced by teen fathers. Moreover, authors adopted narrative literature review as the appropriate research design due to its ability to describe and appraise journal articles and textbooks about a certain topic (Noble \& Smith, 2018; Snyder, 2019). On that score, researchers' collected secondary data from peer-reviewed published articles from various journals. Since there are ample papers on parenthood, the researchers opted for the purposive sampling technique. The selection criteria were also determined by restricted data from the year 2003 to 2021 with an 18 years' projection. The secondary data was sourced from Google Scholar, South African National ETD portal, Jstor, Sabinet and Ebscohost. Then, the data were analysed thematically using thematic analysis.

\section{REVIEW ANALYSIS}

There are a plethora of challenges that come with parenthood, amongst those included are the psychological, social and economic challenges. These challenges know no border as both teen mothers and fathers experienced them. For instance, teen mothers go through turmoil as they transact from being a teenager to being a mother. Equally, Chideya and Williams (2013) signposted that like teen mothers, teen fathers experience turmoil as they have to go through two developmental stages, being teenager and father simultaneously. Moreover, several authors have also reiterated that some of the problems faced by teen fathers emanate from risk factors such as coming from a poor background and suffering from psychological distress (Swartz \& Bhana, 2009; Chideya \& Williams, 2013; Matlakala et al., 2018, Matlakala, 2020). Thus, teen fathers challenges should be understood using teen fathers' lens not those of teen mothers to develop appropriate intervention and support programmes for them. With that being said, this section will discuss the challenges that are faced by teen fathers paying attention to the following point of focus; psychological and socioeconomic challenges of teen fatherhood.

\section{Psychological Challenges}

Numerous psychological effects are brought about by teen fatherhood. However, in this study, those psychological effects are zoomed in on the following aspects: transformative perspective, anxiety, decrease in self-confidence and behavioural changes.

\section{- Transformative perspective}

Parenthood comes with its challenges and requires one to be able to reorganize himself to learn new coping strategies and growth to provide parental care. This reaffirms earlier findings by Knoester and Eggebeen (2006) and Palkovitz and Palm (2009) who underscored that fatherhood warrants teen fathers to start establishing social ties with families and also connect with the labour force. Moreover, young teen fathers tend to need space to figure themselves out after finding out that they are going to be fathers and at times deviate from relating with their families and friends. Some teenagers who become fathers tend to mourn their adolescent phase after realising that they are going to father a child at a young age. In the same vein, Knoester and Eggebeen (2006) and Palkovitz and Palm (2009) avowed that the transformation from adolescence to fatherhood bares a burden on the shoulder of teen fathers thus leading to confusion. Although that is the case, authors believe that other teen fathers do cope with the transition particularly those who are from religious families because they carry with them the pervasive rule of not dwelling on the wrong things. 


\section{- Anxiety}

Teen fatherhood occurs when the teenager is developmentally (according to Erick Erickson) in the stage of identity versus role confusion at the same time becoming a father (Quinlivan \& Condon, 2005). Like adult fathers, teenagers experience anxiety when they are told that they will be teen fathers. The anxiety can be drawn to the fact that they will have to change and care for another being whilst they still need to also be cared for. Again, the inability to provide for one's child might lead to feelings of failure, inadequacy and ultimately suicide. On the same wavelength, Liberska, Deja, Janicka, and Dabek (2016), opined that children depend on their fathers for a precise way of life and they expect them to teach them how to be responsible in life. This in turn functions as a foundation for anxiety and feelings of inadequacy on teen fathers when they realise that they should manage this responsibility. For example, culture posits that fathers should discipline a boy child, teach him responsibility and what it means to be a man. For this reason, teen fathers find themselves bearing a burden because they are also still teenagers who need direction from their fathers. Despite the above, Quinlivan and Condon (2005) found that some teen fathers experience feelings of satisfaction and derive the meaning of life from having and providing for their children. Such teenagers are those who have managed to secure employment; their parents are taking care of their children; as well as those whose partners are taking care of the child without expecting anything from the teen father, such as those who, for instance, impregnated older women.

\section{- Decrease in self-confidence}

External social support systems have an impact on the transition of teen fathers to parenthood. Matlakala et al. (2018) postulate that the perception of family members and friends towards a teenager who is about to be a father is crucial to how the teenager perceives himself. For example, society forbids teenagers from becoming parents at a young age and when the misfortune occurs on the teenager, they find it hard to adapt to the situation at the same time dealing with societal judgement. On the same wavelength, Chideya and Williams (2013) found that several young fathers' selfconfidence often decreases from the time they become teen fathers. Such a decrease is attributed to fear of being judged by other people for having a child as a teenager.

\section{- Behavioural changes}

There is a relationship between teen fathers and mischievous behaviours. Rich (2017) and Matlakala et al. (2018) postulates young fathers engage in behaviours such as stealing, truancy and drug use due to the encumbrance of becoming a father. For instance, when young boys notice that they are going to be fathers, they feel stress and anxiety which leads them to abuse drugs as a coping strategy. Conversely, the inability of securing permanent employment or income has pushed other teen fathers to engage in substance abuse due to stress. Evidently, in a study conducted by Chideya and Williams (2013), it was indicated that some teen fathers, due to stress, used alcohol and/or illicit substances as a coping mechanism. This goes to show that not all teen fathers are pleasant to be assuming the status of fatherhood. However, to Chen, and Harris (2019), the quality of family roles affects teenagers' level of psychological distress. This means that when a teen father does not receive support from his family, he will encounter distress because of a lack of relatedness. Moreover, teenagers who become fathers are also likely to change how they behave. Their behaviour change, Matlakala et al. (2018) compare it to those of civilised men who are in a marriage, as they reduce their involvement in risky behaviours such as smoking, drinking, drug use and dangerous hobbies. Hence fatherhood motivates them to abstain from these activities. This goes to show that other teenagers accept the title of fatherhood with jubilance due to family support.

In contrast, Norman (2017) assert that fatherhood motivates teenagers to engage in the aforementioned risky behaviours. Whereas, Corlyon and Stock (2011) avowed that teen fathers are characterised by an unhappy stage of adolescence and a dislike of school. Nevertheless, it can be deduced that being a father as a teenager assist others to become responsible as they have offspring who they have to live for. Quinlivan and Condon (2005) discovered that some teen fathers experienced stress from the time they learnt that their partners were pregnant. This stress is often caused by the realisation of their incapability to provide for their children, as well as the society's reaction to teen fatherhood, which is often restrictive and disapproving, thus leading to the development of shame and guilt. It is an obvious fact that most African cultures disapprove of teen fatherhood. As such, those teenagers who find themselves on the wrong side of their societal norms are likely to develop these feelings.

\section{Socio-economic Challenges}

The socio-economic challenges pay attention to the social and economic challenges that teen fathers are faced with. In this section, the authors will accentuate the following point of focus; social connection, work involvement, the response of the parents and withdraw of privileges.

\section{- Social connections}

Assuming parental responsibilities might be overwhelming and teenagers are not an exception. Some teen fathers' relationships with their peers might be altered as they develop ties with their children. In support of this, Quinlivan and Condon (2005) and Weber (2012) are both in agreement that having a child changes the nature of one's social life. In other words, teenagers who are fathers will have less free time to spend with their friends or peers, but more time in social relationships that directly or indirectly involve the child. According to Barker as cited in Matlakala et al. (2018), teen fathers frequently face entrenched stereotypes perpetuated by their parents, the parents of their child's mother, the mother herself, and service providers. This is due to the widespread cultural beliefs that an inability to marry the mother 
of one's child is characterised as being irresponsible, even though that is not the case. In some instances, teen fathers fail to maintain contact with their children due to the mother's influences as they fight with the teen father using the child.

\section{- Work involvement}

In the $21^{\text {st }}$ century, maintaining a child is attached to material things. On that score, some teen fathers have seen the need to find some piece jobs in an attempt to maintain their children. World Health Organization (2007), found that the reaction of teen fathers towards fatherhood depends on the employment and/or financial status of the teen father's family. Those who are from less privileged families and unemployed, tend to deny their children as compared to those with means. This can be because having finances makes it easy for one to provide care to his child and also receive sufficient support from his family. On the other hand, teen fathers who are from less privileged families, are coerced to find a job when having a child.

Therefore, becoming a father can add pressure on teen fathers to perform, especially by being able to find employment, which will then enable them to support the child sufficiently. This highlights the kind of roles that society expects the father to play in his child's life. Hence, it can be said that fatherhood has consequences for teenagers' priorities about their economic roles. Snarey, as cited in Forste, Bartkowski and Jackson (2009), found that teen fathers attach themselves to the labour force out of a sense of taking responsibility to provide for their children. However, Worku, Tesema, and Teshale (2021) concur that teen fathers are mainly disadvantaged than adult fathers as they are mainly unemployed and fail to secure money to maintain their children. To make the situation worse, teen fathers find themselves in deprived areas which hinders their prospects for employment. In essence, teen fatherhood may encourage teenagers to seek regular, responsible employment, and this might put a lot of strain on their school work.

\section{- Response of parents}

Parents are the caregivers of teenagers and provide education to teenagers on the issues of mores. According to Kiselia (2008), Sheldrake (2010) and Maiden (2013), there are teen fathers who receive enormous support from their parents, including providing material and social support. As a result of social support from parents, those teen fathers can transact from teenagehood and assume parental responsibilities. To Chobany and Hull (2021) those teen fathers also receive praises from their families as they have proved their manhood. In other instances, authors hold the view that the support of the parents might as well work against teen fathers. Those teen fathers might feel content and continue to bear kids with different women as they never experience hardships of fatherhood at a young age.

\section{- Withdrawal of privileges}

One enjoys the privileges of being young provided by his parents. Equally, in the study conducted by Chideya and Williams (2013), some teen fathers went through turmoil after discovering that they impregnated their partners. This is because their parents resort to withdrawing privileges in the way to prevent them from impregnating more women and take responsibility for their actions. Moreover, the parents prefer channelling their hard-earned money on their well being and leave their child and grandchild in the dugout. On that note, teen fathers are then forced to provide for themselves. In the same limelight, Matlakala (2020) noted that the withdrawal of the privileges makes teen fathers reject the child at birth while others chose a criminal route to provide for their children. That goes to show that teen fathers are, in most instances, not ready to care for themselves and their children. In terms of the Children's Act 38 of 2005 , one of the parental responsibilities is to contribute to the maintenance of the child (RSA, 2005). It is a well-known fact that maintaining a child is very costly. For instance, authors are much aware that children need diapers, milk, doctors and clothes when they are young. All those are quite expensive and with the withdrawal of privileges, they fail to provide that for their kids. That also challenges their manhood, as they hold the notion from their culture and society that they are providers (Billings, \& Macvarish, 2007; Mukuna, 2020).

\section{CONCLUSION}

This paper discussed the concept of teen fatherhood. Authors accentuated that lack of research on teen fathers creates an imbalance and leads people into believing that only teen mothers experience parenthood challenges. However, this study underpinned that due to the lack of research on teen fathers, teen fathers experience various social ills such as stealing and dropping out of school due to the challenge of parenthood. Moreover, the paper emphasised that teen fathers experience psychological, social and economic issues as a result of teen fatherhood. This paper also alluded that fathering a child at a young age has both positive and negative impacts and the perception of young fathers towards fatherhood are limited by the burden of financially providing for their children. The authors recommend social practitioners develop primary intervention methods that aim at addressing teen fatherhood. The emphasis should be based on educating teenagers about teen fatherhood and its likely consequences to the teen father. Moreover, future research can focus on the survival of a boy child raised by a single mother.

\section{LIMITATION AND STUDY FORWARD}

The research findings are limited to the literature on teen fatherhood and cannot be generalised as universal challenges.

\section{AUTHORS CONTRIBUTION}

K. M. Rantho: She drafted the manuscript and wrote the first draft as the lead author. 
F. K. Matlakala: The author was responsible for supervising the student and making the final product of this manuscript.

\section{REFERENCES}

1. Berger, L.M., \& Langton, C.E. (2011). Young Disadvantaged Men as Fathers. The ANNALS of the American Academy of Political and Social Science, 635(1), 56-75. https://doi.org/10.1177/0002716210393648

2. Billings, J., \& Macvarish, J. (2007). Teenage Parents' Experiences of Parenthood and Views of Family Support Services in Kent. Canterbury: University of Kent.

3. Chen, P., \& Harris, K. M. (2019). Association of positive family relationships with mental health trajectories from adolescence to midlife. JAMA pediatrics, 173(12), e193336-e193336. https://doi.org/10.1001/jam apediatrics.2019.3336

4. Chideya, Y., \& Williams, F. (2013). Adolescent Fathers: Exploring their perceptions of their role as a parent. Social Work/Maatskaplike Werk, 49(2). 209-221. https://doi.org/10.15270/49-2-65

5. Chili, S. (2013). Perspectives and Experiences of Fatherhood among Young People: A Case Study of 'Black' Students at the University of KwaZulu-Natal in Durban, KwaZulu-Natal. http://hdl.handle.net/10413/10047

6. Chobany, M., \& Hull, D. (2021). The Stigmas Associated With Teen Parenting: How Gender-Stereotypical Expectations Contribute. Psi Chi Journal of Psychological Research, 26(1). https://doi.org/10.24839/23257342.JN26.1.21

7. Corlyon, J., \& Stock, L. (2011). Teenage Parenting: Reference Manual: A report prepared for Community Care Inform.

8. Dudley, J.R. (2007). Helping Non-Residential Fathers: The case for teen and unmarried fathers. Families in Society, 88(2).171-181. https://doi.org/10.1606/1044-3894.3615

9. Fagan, F., Bernd. E., \& Whiteman, V. (2007). Adolescent Fathersee Parenting Stress, Social Support and Involvement with Infants. Journal of Research on Adolescence, 17(1), 1-22. https://doi.org/10.1111/j.15327795.2007.00510.x

10. Fletcher, J.M., \& Wolfe B.L. (2012). The effects of teenage fatherhood on young adult outcomes. Economic Inquiry, 50, 182-201. https://doi.org/10.1111/j.1465-7295.2011.00372.x

11. Forste, R., Bartkowski, J.P., \& Jackson, R.A. (2009). Just Be There For Them: Perceptions of Fathering among Single, Low-income Men. Fathering. 7(1), 49-69. https://doi.org/10.3149/fth.0701.49

12. Glikman, H. (2004). Low-income young fathers: contexts, connections, and self. Social Work, 49(2), 195-206. https://doi.org/10.1093/sw/49.2.195

13. Hodgson, S., Painter, J., Kilby, L., \& Hirst, J. T. (2021). The Experiences of First-Time Fathers in Perinatal Services: Present but Invisible. Healthcare, 9(161), 1-12. https://doi.org/10.3390/healthcare9020161.

14. Kiselia, M.S. (2008). When Boys Become Parents. New Brunswick: Rutgers University Press. https://doi.org/10.36019/9780813545790

15. Knoester, C., \& Eggebeen, D. J. (2006). The effects of the transition to parenthood and subsequent children on men's well-being and social participation. Journal of Family Issues, 27(11), 1532-1560. https://doi.org/10.1177/0192513X06290802

16. Liberska, H., Deja, M., Janicka, M., \& Dąbek, K. (2016). The emotional state of "young" fathers. Current Issues in Personality Psychology, 4(4), 217-227. https://doi.org/10.5114/cipp.2016.63219

17. Madiba, S., \& Nsiki, C. (2017). Teen fathers perceptions and experiences of fatherhood: A qualitative exploration with in-school teen fathers in a rural district in South Africa. Current Pediatric Research, 21(3), 501-506.

18. Maiden, B.S. (2013). The Lived Experiences of the Adolescent Father in Northern Virginia. Virginia Polytechnic Institute: State University.

19. Mukuna, R. K. (2020). Exploring Basotho teenage fathers' experiences of early fatherhood at South African rural high schools. Journal of Psychology in Africa, 30(4), 348-353. https://doi.org/10.1080/1433 0237.2020 .1796031

20. Noble, H., \& Smith, J. (2018). Reviewing the literature: choosing a review design. Evidence-Based Nursing, 21(2), 39-41. https://doi.org/10.1136/eb-2018-102895

21. Norman, J. (2017). Implications of parenting behaviour and adolescent attachment for understanding adolescent sexting (Doctoral dissertation, University of Windsor (Canada)).

22. Palkovitz, R., \& Palm, G. (2009). Transitions within fathering. Fathering, 7(1), 3. https://doi.org/10.3149/ft h.0701.03

23. Quinlivan, J. A., \& Condon, J. (2005). Anxiety and depression in fathers in teenage pregnancy. Australian \& New Zealand Journal of Psychiatry, 39(10), 915-920. https://doi.org/10.1080/j.1440-1614.2005.01664.x

24. Republic of South Africa [RSA]. 2005. Children's Act 38 of 2005. Government Gazette: Government Print.

25. Rich, E. G. (2017). Exploring perceived reasons and risk factors for illicit drug use among youth in the Western Cape: Implications for primary prevention. $\mathrm{PhD}$ thesis. University of the Western Cape.

26. Sheeran, N., Jones, L., Bernardin, S., Wood, M., \& Doherty, L. (2021). Immoral, Incompetent, and Lacking Warmth: How Stereotypes of Teenage Fathers Compare to Those of Other Parents. Sex Roles, 84(5), 360-375. https://doi.org/10.1007/s11199-020-01172-8

27. Sheldrake, E.S. (2010). The Experiences of Being a Teenage Father: An Interpretative Phenomenological Analysis. Birmingham: University of Birmingham. 
28. Snyder, H. (2019). Literature review as a research methodology: An overview and guidelines. Journal of business research, 104, 333-339. https://doi.org/10.1016/j.jbusres.2019.07.039

29. Swartz, S., \& Bhana, A. (2009). Teenage Tata: Voices of young fathers in South Africa. Cape Town: Human Sciences Research Council. http://hdl.handle.net/20.500.11910/4721

30. Tyawa, G. (2017). Fatherhood and money: the experiences of unemployed fathers and their navigation of fatherhood in Soweto (Doctoral dissertation). University of the Witwatersrand.

31. Weber, J. B. (2012). Becoming teen fathers: Stories of teen pregnancy, responsibility, and masculinity. Gender \& Society, 26(6), 900-921. https://doi.org/10.1177/0891243212459074

32. Worku, M.G., Tesema, G.A., \& Teshale, A.B. (2021). Prevalence and associated factors of adolescent fatherhood in Ethiopia: A multilevel analysis using the 2016 Ethiopian demographic health survey data. PLoS ONE, 16(3), e0249024. https://doi.org/10.1371/journal.pone.0249024

33. World Health Organization [WHO]. (2007). Fatherhood and Health outcomes in Europe. World Health Organization. 